\title{
ALGUNOS APUNTES GENERALES SOBRE EL CABALLERO ORFEO
}

\section{Some general notes on Sir Orpheus}

\author{
José Antonio Alonso Navarro ${ }^{1}$
}

Recibido 02/10/2012

Aceptado 02/12/2019

\begin{abstract}
RESUMEN
El propósito principal de este artículo es introducir al lector moderno al poema medieval inglés del caballero Orfeo (Sir Orfeo) en cuanto a sus orígenes, autoría, manuscritos existentes, argumento, personajes, su relación con el mito griego clásico de Orfeo y su relación con el folclore celta en referencia al Otro Mundo. El enfoque del artículo es eminentemente exploratorio, descriptivo e informativo y está motivado, por lo tanto, por la necesidad de contextualizar el poema medieval inglés desde el punto de vista histórico y literario antes de que el lector aborde una lectura preliminar del mismo. La introducción, así pues, ofrecerá una visión general interna y externa del poema inglés y se centrará brevemente en comparar la relación interpersonal entre Orfeo y Eurídice como personajes y la relación intrapersonal de Orfeo y Eurídice con el inframundo griego con esta misma interacción que se establece entre Orfeo y Eurídice como personajes y Orfeo y Eurídice (Heurodis) con el Otro Mundo de estilo celta del poema inglés.
\end{abstract}

Palabras claves: Orfeo, Sir Orfeo, mitología griega, mitología irlandesa, mitología galesa, folclore celta, el Otro Mundo celta.

\begin{abstract}
The main purpose of this article is to introduce the modern reader into the medieval English poem Sir Orfeo as to its origins, authorship, extant manuscripts, argument, characters, its relationship with the classical Greek myth of Orpheus and its relationship with the Celtic folklore in reference to the Otherworld. The approach of the article is eminently exploratory, descriptive, and informative, and is spurred, therefore, by the need to contextualize the medieval English poem from the historical and literary viewpoint before the reader carries out a preliminary reading of it. The introduction, therefore, will offer a general internal and external outlook of the English poem, and will briefly compare the interpersonal relationship between Orpheus and Eurydice as characters and the intrapersonal relationship between Orpheus and Eurydice with the Greek Underworld with this same interaction established between Orpheus and Heurodis as characters and Orpheus and Heurodis with the Celtic-style Otherworld of the English poem.
\end{abstract}

Keywords: Orpheus, Sir Orfeo, Greek mythology, Irish mythology, Welsh mythology, Celtic folklore, Celtic Otherworld.

En la introducción escrita por las ${ }^{2}$ editoras Anne Laskaya y Eve Salisbury para la versión digital del caballero Orfeo (Sir Orfeo), leemos que la versión conocida más antigua en inglés medio (Middle English) de este poema inglés se conserva en el manuscrito Auchinleck, que data aproximadamente de 1330-40. Además, se nos dice que fue elaborado para lectores adinerados, pero que no pertenecían a la aristocracia. En cuanto a su autor, se desconoce por completo, pero sí se sabe que por sus peculiaridades lingüísticas El caballero Orfeo fue compuesto a finales del siglo XIII o principios del siglo XIV dentro de la zona de Westminster-Middlesex. También se desconoce la existencia de una fuente cercana de la que

\footnotetext{
${ }^{1}$ Universidad del Norte meildeja@yahoo.com

${ }^{2}$ Laskaya, Anne \& Salisbury, Eve, ed. Teams Middle English Texts Series. The University of Rochester. https://d.lib.rochester.edu/teams/text/laskaya-and-salisbury-middle-english-breton-lays-sir-orfeo-introduction. (From The Middle English Breton Lays. 1995).
} 
pudiera haber bebido el poema inglés, aunque, como apuntan Laskaya y Salisbury (1995), la mayoría de los autores suponen que debía de haber existido en algún momento una fuente en francés antiguo.

Existen referencias a un lay musical de Orfeo en varios textos en francés antiguo. Laskaya y Salisbury mencionan el romance del siglo XII Floire et Blanceflor ("le lai d'Orphey", en el verso 855), el Lai de l'Espine ("Le lai lor sone d'Orphei”, en el verso 181) y el Lanzarote en prosa de La Vulgata ("lay d'orfay"). No es difícil asociar el nombre de Orfeo con el mito griego clásico, mito que en el poema medieval inglés se readaptará incorporando elementos de la mitología y del folclore celta (y también germánico) en torno al mundo sobrenatural de las hadas procedentes de los layes bretones de escritores en francés antiguo, como los compuestos por María de Francia en el siglo XII.

El caballero Orfeo se enmarca dentro de los layes bretones compuestos en inglés medio (Middle English) en los siglos XIII y XIV. Estos forman parte de los romances medievales ingleses y franceses. Suelen constar, en general, de unos 600-1000 versos y relatan historias de amor y caballería que poseen elementos y motivos recurrentes celtas, como veremos, relacionados sobre todo con el mundo de las hadas y de lo sobrenatural. El término lay o lai podría derivar o bien del alto y/o medio antiguo alemán leich (melodía, canción) o bien del vocablo irlandés laid (canción), como sugiere Zipes (2009). Este autor, además, apunta que las leyendas artúricas podrían haberse asentado en Bretaña desde Gales, Cornualles e Irlanda (quizá a partir del siglo IX o antes), y en el continente estos layes podrían haberse expandido inicialmente como canciones a través de trovadores y arpistas. Parece que el lay más antiguo registrado corresponde al de Robert Biket ("lai du cor"), que data de entre mediados a finales del siglo XII. Robert Biket fue un escritor anglo-normando que vivió entre los siglos XII y XIII. Compuso su Lai du cor en Inglaterra hacia 1170-80 como una sátira o parodia contra los ideales caballerescos del ciclo artúrico al contar la historia de un cuerno que rehúsa servir vino a los maridos cornudos o engañados.

El Lai du cor es un poema breve que contiene menos de 600 versos compuestos en anglo-normando o francés de oïl, que era el tipo de francés que se hablaba en Inglaterra tras la conquista normanda de 1066. La historia de este lay comienza con la llegada a la corte del rey Arturo de un criado enviado por el rey escocés Mangon de Moraine, que entrega al rey Arturo un cuerno mágico que no sirve vino a quienes son engañados por sus esposas infieles. Los caballeros y señores tratan de advertir al rey que tenga cuidado con su decisión, pero este desatiende las advertencias y consejos de sus caballeros y trata de beber del cuerno, pero no puede, el vino se le derrama irremediablemente. La reina Ginebra busca la forma de arreglar la situación y a duras penas lo consigue. Tras el incidente, el rey Arturo insta a todo el mundo a beber y todos aquellos que lo hacen acaban mojados en vino. El resultado pone de manifiesto que casi todos los caballeros han sido engañados, excepto Caradoc y su fiel esposa. En la actualidad, este poema se conserva en la Biblioteca Bodleian de la Universidad de Oxford en el manuscrito Digby 86.

A partir del siglo XII los layes bretones comienzan a adquirir estatus de género literario con María de Francia, mencionada más arriba, hasta consolidarse ya como género literario a partir del siglo XIII. Se cree que los layes de esta autora fueron compuestos en torno a 1170. María de Francia vivió en Inglaterra durante el reinado de Enrique II entre los siglos XII y XIII, respectivamente. Los layes de María de Francia tendrían su origen en los layes bretones anteriores de origen celta cantados por trovadores bretones (como se dijo antes, quizá en o a partir del siglo IX o antes) que no se han conservado, y que contendrían un resumen introductorio de la historia que serviría como inicio o para marcar el contexto del propio lay como canción, resumen que formaría posteriormente, a su vez, la base para el lay 
narrativo. Durante los siglos XIII y XIV varios autores ingleses compusieron en Inglaterra layes bretones en inglés medio (Middle English), entre ellos Thomas Chestre. María de Francia escribió unos doce layes bretones más o menos breves en octosílabos basados, sobre todo, en el concepto del amor cortés y en las aventuras de varios caballeros. El manuscrito en el que se conservan los doce layes completos de María de Francia es el Harley 978, un manuscrito del siglo XIII que se guarda en la Biblioteca Británica.

El manuscrito Harley consta de un prólogo de 56 versos en el que María de Francia explica que la motivación o el deseo que la llevó a escribir los layes fue seguir el ejemplo de los antiguos griegos y romanos y, por lo tanto, esto la llevó a escribir historias que fueran entretenidas y didácticas, morales o provechosas, así como conservar para la posteridad las historias que había oído. Esta es la lista de layes que contiene el manuscrito Harley 978: Guigemar, Equitan, Le Fresne, Bisclavret, Lanval, Les Deux Amants, Yonec, Laüstic, Milun, Chaitivel, Chevrefoil y Eliduc. Entre los layes bretones en inglés medio más destacados mencionamos el de: Sir Orfeo, Sir Degaré, Sir Gowther, Emaré, Sir Launfal y The Erle of Toulouse. En los Cuentos de Canterbury de Geoffrey Chaucer es posible destacar uno que lleva por título The Franklin's Tale.

En el mito griego, Orfeo, hijo de Apolo y de Calíope, una musa, bajó al inframundo para rescatar a su esposa Eurídice cuando fue mordida por una serpiente al huir del pastor y rival de Orfeo, Aristeo. En su viaje o catábasis, Orfeo tuvo que enfrentarse a muchos peligros, pero con su música logró salir victorioso de todos ellos hasta que llegó hasta el lugar donde se hallaban Hades y Perséfone, los cuales, conmovidos por la actitud de Orfeo, permitieron finalmente a Eurídice que volviera con aquel al mundo de los vivos, pero con la condición de que él caminase delante de ella, y no se diera la vuelta para mirarla hasta haber salido por completo del inframundo y los rayos de sol hubieran caído sobre la mujer. Sin embargo, cuando Eurídice estuvo ya a un pequeño paso de llegar al mundo superior, Orfeo, que ya no pudo resistir el deseo de ver a su esposa, se dio la vuelta para mirarla y esta se desvaneció en el aire para siempre.

A través de Ovidio sabemos que Orfeo intentó regresar al inframundo, pero como Caronte no le permitió pasar por el río Leteo, Orfeo decidió marcharse a los montes Ródope y Hemo. Las bacantes tracias, que fueron rechazadas por él, lo apedrearon y despedazaron. Su cabeza y su lira fueron arrojadas al río Hebro (Evros) en Tracia. Cerca de Lesbos una serpiente quiso comerse la cabeza de Orfeo, pero Apolo la convirtió en roca. No obstante, el final de Orfeo es tan feliz como esperanzador al lograr este reunirse finalmente con Eurídice en el inframundo para toda la eternidad.

En la versión de Eratóstenes y que procede de la obra perdida de Esquilo, Las basárides, Orfeo, tras ser despedazado por las ménades, fue enterrado por unas ninfas en un lugar llamado Libetra, próximo al Olimpo. En el poema medieval inglés la acción no transcurre en la Grecia clásica, sino en Inglaterra. Eurídice (Heurodis) no muere, sino que es raptada por el rey de las hadas. Cuando esto sucede, Orfeo, rey de un reino medieval inglés, designa a su fiel mayordomo real para que gobierne en su lugar y da instrucciones al pueblo para que elija un parlamento y nombre un nuevo rey en caso de que este muera. Posteriormente, tras renunciar a todo, a su reino y sus riquezas, Orfeo se coloca el manto del peregrino tan característico en la Edad Media, coge su lira, y se marcha voluntariamente al exilio. Al cabo de diez años de vida errante, un día descubre a Eurídice montada a caballo y participando en una partida de caza del rey de las hadas y se dispone a seguirla en un viaje que no conduce al infierno, sino al Otro Mundo (orbis alia) o Más Allá celta. Este Otro Mundo propio de la mitología celta nos remite al reino de las deidades especialmente y, quizá también, al de los muertos.

En la mitología gaélica y de los britanos, el Otro Mundo suele describirse como un reino sobrenatural en el que prevalece la juventud eterna, la hermosura, la salud, la 
abundancia o riqueza y la felicidad. Sin embargo, este entorno sobrenatural no está al alcance de todo el mundo, pues solamente unos pocos elegidos pueden acceder a él. Este es el caso de ciertos héroes propios de la mitología celta como Cúchulainn (Irlanda), Fionn o Fionn mac Cumhaill (Irlanda) o Bran o Bran mac Febal (Irlanda), que logran penetrar en él bien casualmente o tras ser invitado por alguno de sus habitantes sobrenaturales o mágicos. Y su acceso es posible a través de cuevas o antiguos túmulos, debajo del mar, debajo de un lago, a lo largo y ancho del mar occidental, o viajando más allá del confín de la tierra. En general, el Otro Mundo suele hallarse en una isla o debajo de la tierra. El paso de este mundo al otro puede manifestarse a través de señales o fenómenos naturales y/o sobrenaturales, como la aparición de niebla, cambios repentinos en el tiempo, y lo más frecuente, quizá, la aparición de seres divinos o animales atípicos.

Existen casos en los que una mujer invita al héroe a visitar el Otro Mundo tras ofrecerle una manzana, una rama argenta de manzana, o un ovillo que ha de seguir este mientras se vaya desenrollando. En la mitología galesa el Otro Mundo recibe el nombre de Annwyn y en la mitología irlandesa los nombres de Tír na nÓg, Tech Duinn, Emain Ablach, Tír nAill, Tír Tairngire, Tír fo Thuinn, Tír na mBeo, Mag Findargat, Mag Argatnél, Mag Ildathach, Mag Cíuin, Tír na mBan o La TierralIsla de las Mujeres, El Paraíso de las Aves, Mag Mell (Magh Meall) o La Isla de la Alegría y La Isla de los Benditos o Bienaventurados. En el Otro Mundo habitan los seres sobrenaturales o dioses llamados Tuatha Dé Danann. En la leyenda artúrica resulta muy popular un lugar conocido como Avalon. Como se dijo antes, al Otro Mundo se accede normalmente a través de túmulos antiguos, como los situados en Brú na Bóinne y Cnoc Meadha, los cuales reciben el nombre de sídhe, término que podría traducirse como "moradas del Otro Mundo", esto es, las moradas de los dioses, conocidas posteriormente como aos sí o daoine sí ("la gente del Otro Mundo").

En los immrama irlandeses, puede leerse cómo una hermosa y joven mujer del Otro Mundo se acerca al héroe del relato y le refiere cantando la noticia de una tierra llena de felicidad. Algunas veces la mujer le ofrece al héroe una manzana o la promesa de su amor a cambio de que este la ayude en una batalla. Él la sigue a través del mar para no ser vistos jamás. Este viaje suele realizarse en un barco de cristal, en un carro o a caballo. Esta mujer puede tratarse de la diosa Niamh o la diosa Fand. Oisín o Osheen es un claro ejemplo de héroe irlandés muy popular. Aparece como guerrero en el Ciclo de Fionn de la mitología irlandesa. Se trata del hijo de Fionn mac Cumhaill y de Sadhbh. En el relato de aventuras (o echtra) que lleva por título Oisín in Tír na nÓg, este héroe es visitado por un hada llamada Niamh Chinn Óir, una de las hijas de Manannán mac Lir, un dios del mar.

El padre de Niamh convirtió la cabeza de esta hada en la cabeza de un puerco a causa de una profecía. Ella le refiere esta circunstancia a Oisín y le hace saber que ella recuperaría su forma original si este se casaba con ella. El héroe accede y regresan a Tír na nóg ("la tierra de la juventud"), también conocida como Tír Tairngire ("la tierra de promisión"), donde Oisín se convierte en rey. De la unión de este matrimonio nacen Oscar, Finn y Plor na mBan. Después de 300 años, que a Oisín le parecen tres, Oisín decide volver a Irlanda con el fin de ver a sus antiguos camaradas. Una versión de la historia dice que Oisín, al tratar de levantar una piedra grande, se cayó de Embarr, el caballo blanco que su esposa Niamh le había dado y del que esta le había advertido que no debía desmontar para no hacerse viejo; circunstancia esta que hizo que Oisín envejeciera finalmente.

En la mitología galesa, el Otro Mundo, como apuntamos más arriba, se llama Annwyn o Annwfn y está gobernado por los reyes Arawn y Gwyn ap Nudd (este último en la literatura artúrica). El Otro Mundo galés se destaca por tratarse de un mundo de placeres en el que abunda la comida y existe la juventud eterna. En el poema medieval galés Preiddeu Annwfn, que se encuentra recogido en el Libro de Taliesin, se describe el viaje conducido por el rey 
Arturo a varios reinos del Otro Mundo (Annwn en la mitología galesa) con el fin de recuperar un caldero mágico que tiene como propiedad proporcionar abundante comida.

La entrada de Annwn como un reino subterráneo estaba situada en el Otero de Glastonbury, aunque, en ocasiones, este mundo sobrenatural galés se describía como una isla paradisíaca situada al otro lado del océano, al igual que en la mitología irlandesa en la que, como ya dijimos, destacan las islas Tír na nÓg o Tír na mBeo. Cuando en El Caballero Orfeo el rey Orfeo llama a la puerta del Otro Mundo vestido como un trovador mendigo, este logra sortear al guardián de la puerta, atravesar el valle de los muertos y, finalmente, poder cantar al rey de las hadas. Hecho esto, el rey de las hadas le da a Orfeo la posibilidad de pedir una especie de "merced" o dádiva, y este solicita que le devuelvan a Eurídice. Y aunque en un principio el rey de las hadas duda, este acaba por ceder, produciéndose el reencuentro entre Orfeo y Eurídice (lo que en la tradición literaria se denomina anagnórisis o agnición). El poema acaba con el regreso al hogar de Eurídice por parte de Orfeo y la vuelta de este último al trono, lo cual pone de relieve el alejamiento de este lay bretón compuesto en inglés medio de la versión griega clásica.

Laskaya y Salisbury (1995) nos recuerdan en su introducción a la versión digital de $E l$ caballero Orfeo acerca de la recurrencia de los motivos propios del folklore tradicional, como, por ejemplo, el viaje al Otro Mundo, el hombre que pierde a su esposa o amada, la "merced" o la dádiva, el modelo del exilio-regreso, y la parte en la que ${ }^{3}$ un señor o caballero comprueba la lealtad de sus súbditos más cercanos. La estructura del poema, de alguna manera, se ha construido en base a binomios opuestos, como la pérdida y el restablecimiento, el dolor y el regocijo, la riqueza y la pobreza, etc., como también hacen notar Laskaya y Salisbury en su introducción. El caballero Orfeo (Sir Orfeo) se conserva en tres manuscritos. El más antiguo, como se dijo más arriba, en el Auchinleck (MS) de aproximadamente 1330 (siglo XIV), que también recibe la denominación de Advocates 19.2.1; otro segundo manuscrito, el llamado Harley 3810, que es de principios del siglo XV, y un tercero, el Ashmole 61, cuya versión del Caballero Orfeo data de alrededor de 1488.

El caballero Orfeo, en su versión en inglés medio, constituye, como ya apuntamos, un lay de estilo bretón que llegó a Inglaterra a través de los layes bretones escritos en anglonormando (o francés antiguo) por María de Francia. Una de las obras que podrían haber tenido una posible influencia en el poema medieval inglés podría haber sido The Wooing of Etain. Étaín es un personaje que procede de la mitología irlandesa descrita como una mujer de gran belleza tanto física como espiritual que logra enamorar a un ser del mundo sobrenatural. Étaín, que es la hija del rey Ailill, se convierte en la esposa de un ser sobrenatural primero (Midir) y, posteriormente, de un mortal (Eochaid Feidlech). Étaín es una mujer de cabellos dorados, de ojos azules, poseedora de una piel tan blanca como la nieve y de mejillas de un intenso color rojizo. Uno de los paralelismos más evidentes que surge entre ambas obras es la presencia del mundo sobrenatural y su relación con el mundo de los seres humanos. En este caso, Étaín participa del mundo sobrenatural al casarse con Midir, un ser del mundo de los Tuatha de Danann (o tribus de la diosa Danu).

Un resumen del argumento del poema mucho más detallado es el siguiente. El caballero Orfeo, rey de un reino en Inglaterra, pierde a su esposa Eurídice cuando esta es raptada por el rey de las hadas. Todo ocurre cuando Eurídice se queda dormida en un huerto bajo un árbol y en su sueño es visitada por el rey del Otro Mundo, que expresa su intención de llevársela a su reino. Al día siguiente, Eurídice pide la ayuda de un grupo de caballeros para que la proteja, sin embargo, a pesar de ello, Eurídice desaparece por completo. Tras lo

\footnotetext{
${ }^{3}$ Esto último se da también en El caballero Orfeo, cuando Orfeo se disfraza para comprobar la lealtad de su mayordomo real.
} 
sucedido y afectado por dicha circunstancia, Orfeo abandona su reino y comienza una prolongada andadura en solitario por un bosque, dejando a cargo de los asuntos de gobierno, a su mayordomo real. Además, Orfeo deja instrucciones precisas de que se reúna al parlamento y se elija un nuevo rey en caso de que este muera.

El caballero Orfeo vaga por el bosque durante diez años, durmiendo a la intemperie y alimentándose de bayas y frutos en verano y de raíces y la corteza de los árboles en invierno. Pasado todo este tiempo, descubre a Eurídice cabalgando en compañía de sesenta damas entretenidas en la práctica de la cetrería junto a un río. Sigue entonces a tales damas hasta un acantilado y recorre unas tres millas a través de la roca hasta llegar al reino de las hadas (o al mundo sobrenatural/al Otro Mundo). Este mundo sobrenatural se presenta como una campiña en la que destaca un fabuloso castillo hecho de oro y cristal. El guardián del castillo le permite la entrada al mismo y en su interior contempla a personas "de las que se pensaba que estaban muertas, pero que, en realidad, no lo estaban". Entre estas personas ve dormida a su esposa Eurídice. El rey reprende a Orfeo por haber entrado en el castillo sin ser llamado, y este decide entretenerlo tocando el arpa. La música agrada al rey y este le ofrece a Orfeo la posibilidad de que le pida algo a cambio. Orfeo elige a Eurídice y el rey, a pesar de su reserva inicial, accede, permitiendo que Orfeo se lleve a Eurídice a Inglaterra.

Al llegar a Winchester, ciudad de Orfeo, este deja a Eurídice en un lugar seguro y se viste con las ropas de un mendigo. Se dirige a su castillo y su mayordomo real, sin saber tampoco quién es, le permite entrar al castillo en calidad de músico para que toque el arpa. Cuando a Orfeo le hacen saber que se trata del arpa del rey, este aprovecha la ocasión para comprobar la lealtad de su mayordomo y revela que encontró el arpa hace diez años junto al cuerpo mutilado de un hombre que había sido devorado por leones y lobos. Al escuchar esto, el mayordomo se desmaya presa de la aflicción. Es entonces cuando el mendigo hace saber a todos que se trata del propio rey Orfeo. Cuando el mayordomo vuelve en sí, Orfeo confiesa a su mayordomo que si este se hubiera alegrado de su muerte hubiera mandado echarlo de su reino. Finalmente, el caballero Orfeo manifiesta su intención de convertirlo al mayordomo en su heredero y se manda traer a Eurídice al castillo.

Los tres manuscritos en los que se conserva El caballero Orfeo presentan algunas diferencias a pesar de que ambos poseen un contenido similar en cuanto al argumento de la historia. En el manuscrito Ashmole la esposa del rey Orfeo se llama Meroudys y en el manuscrito Auchinleck se llama Heurodus. El manuscrito Auchinleck consta de 332 hojas de vitela, muchas de las cuales se han cortado. Sin embargo, se ha logrado recuperar, al menos, ocho de tales hojas. Se considera que el manuscrito Auchinleck es el que más se aproxima al original y se le conoce como el "texto base". Contiene unos 604 versos. El manuscrito Harley 3180 contiene unos 34 folios de papel y la versión del Caballero Orfeo consta de 509 versos. En cuanto al manuscrito Ashmole 61, este contiene 162 folios de papel.

Un aspecto bastante interesante común, en general, a los tres manuscritos es que el Otro Mundo se parece más a un mundo situado en una dimensión paralela que a un mundo o "universo"/"entorno" infernal asociado al mundo de los muertos regido por el dios Hades, como en el mito griego de Orfeo y Eurídice. En este sentido, por lo tanto, el Otro Mundo que aparece en el poema inglés y que posee una clara influencia celta no es el mundo de los muertos, sino un mundo al que puedan acceder personas vivas, que aún no han muerto o, en muchos casos, personas que están al borde de la muerte, como han indicado especialistas como D. Allen. En la versión inglesa del Caballero Orfeo, Orfeo es un rey inglés, es decir, se trata de un personaje adaptado a un contexto histórico y local más moderno (la historia se desarrolla en Tracia, que en el poema inglés se presenta como el nombre antiguo de Winchester) alejado del contexto local presentado en la literatura griega clásica, aunque, sin duda alguna, existen algunas analogías entre el Orfeo inglés y el Orfeo griego. En primer lugar, a ambos les une la música, en especial, su pasión por el arpa, que ambos tocan con gran 
maestría y pericia musical, causando el arrobo y fascinación de cuantos los escuchan: hombres y bestias. Las esposas de ambos muestran una gran fidelidad hacia ellos, evitando entregar su corazón a otros hombres que las cortejen.

En la versión clásica, Orfeo busca a Eurídice cuando es consciente de su ausencia, al igual que el rey inglés, que decide exiliarse de su reino y marcharse lejos cuando echa en falta a su esposa. Y en ambas versiones, ambos personajes viajan hasta el mundo subterráneo (el Orfeo griego al inframundo y el Orfeo inglés al mundo/Otro Mundo de las hadas) con el fin de traer de vuelta a sus respectivas esposas. Y en ambos casos, durante el periplo de rescate, los dos personajes se enfrentan a no pocas dificultades y obstáculos que requieren tañer el harpa prodigiosamente con el fin de vencerlos. En cuanto a las diferencias más señaladas, se destaca el hecho de que mientras el Orfeo inglés no desciende directamente de los dioses, el Orfeo griego sí. Por otro lado, al Orfeo inglés no se le exige que no mire atrás para ver a su esposa durante el viaje de regreso al mundo de los humanos, en cambio, al Orfeo griego sí se le exige dicha condición. En relación con personaje femenino, Eurídice, esta muere en el mito clásico antes de descender al Hades griego, mientras que en el poema inglés del Caballero Orfeo, esta es raptada viva, pero no muere. Y en última instancia, El caballero Orfeo tiene un final feliz a diferencia del Orfeo del mito griego clásico. En el primer caso, el rey inglés logra recuperar viva a su esposa, mientras que, en el segundo caso, el Orfeo griego pierde a su esposa al mirar atrás (y romper de este modo la condición impuesta por Hades) antes de llegar al mundo de los seres humanos.

A través de la página web de Teams Middle English Texts es posible acceder también a la versión digital del Caballero Orfeo a cargo del profesor George Shuffelton. La versión impresa está disponible también en el libro de 2008 Codex Ashmole 61. A Compilation of Popular Middle English Verse (publicado igualmente por el profesor Shuffelton). En la introducción a la versión digital, el profesor Shuffelton nos brinda algunos datos interesantes acerca del Caballero Orfeo, que complementan los proporcionados por las profesoras Laskaya y Salisbury. Al hablar de los tres manuscritos existentes, Shuffelton (2008) apunta que los mismos no indican por sí solos que hubiera existido una amplia recepción del poema medieval inglés, puesto que entre la copia de un manuscrito a otro había un lapso de tiempo general de unos cincuenta años y, además, en tres regiones diferentes: Londres, Warwickshire y Leicestershire.

Asimismo, Shuffelton señala que el mito del Orfeo griego, que se conocía en la Edad Media a través de los textos clásicos como los de Ovidio (Metamorfosis X) y Virgilio (Geórgicas IV), incluye "adaptaciones" o actualizaciones de Boecio, (Fabio Plancíades) Fulgencio, Guillermo de Conches, Nicholas Trivet, Boccaccio, Cristina de Pizán y Robert Henryson. Tales adaptaciones dieron como resultado distintos enfoques o interpretaciones del texto, en especial, una de tipo filosófico o cristiana. Shuffelton menciona el Ovide Moralisé, una adaptación anónima en verso de las Metamorfosis de Ovidio en francés antiguo hecha a comienzos del siglo XIV, de unos 72.000 versos octosílabos y atribuida a Philippe de Vitry. Asimismo, Shuffelton menciona el Ovidio moralizado (Ovidius Moralizatus) de Pierre Bersuire o Pierre Bercheure (c. 1290-1362) escrita en 1340. Bersuire fue un traductor y enciclopedista francés de la orden de los benedictinos al que se suele atribuir el Gesta Romanorum, y se le considera el autor de Repertorium morale, obra aparecida antes de 1355 e impresa en Colonia (1477), Nuremberg (1489), Lyon (1517), Parías (1521), Venecia (1589) y Amberes (1609), entre otros países, Reductorium morale o Liber Bibliae Moralis, que consta de treinta y cuatro libros e Inductorium morale biblicum, que incluye dieciséis libros sobre Dios y el mundo. El Ovidius Moralizatus es una obra de mitografía terminada en el año 1340. El aporte de Bersuire a este respecto fue moralizar la obra pagana de Ovidio. Las historias contenidas en esta obra influyeron en Geoffrey Chaucer y en una de sus obras más sobresalientes, Los Cuentos de Canterbury. 
En Ovidius Moralizatus, apunta Shuffelton, Orfeo, o bien se convierte en Cristo redentor que salva a la humanidad de la muerte, o bien representa a la humanidad pecadora. En este último caso, Orfeo perdería su alma, simbolizada en Eurídice, al caer en el pecado, aunque este tipo de interpretaciones, según Shuffelton, plantean algunas contradicciones, como la que declara a Orfeo pecado sin mencionarse o aclararse lo suficientemente bien su pecado, aunque pueda pensarse que se trata del pecado de soberbia, contradicciones o dificultades que surgen debido a "the poem's fusion of the Orpheus myth to the form and style of the Breton lay." En relación con las semejanzas que posee El Caballero Orfeo con aspectos vinculados a la pérdida y posterior recuperación de la familia, a la visión o el concepto del matrimonio, a la recurrencia a ciertos motivos folclóricos, al tratamiento de valores humanos como el sacrificio, la paciencia y la gracia, al rescate de una dama-heroína y a los aspectos siniestros del mundo sobrenatural (o del Otro Mundo), Shuffelton señala su parecido con ${ }^{4}$ Sir Isumbras), Saint Eustace, How the Good Wife Taught Her Daughter, ${ }^{5}$ Sir Corneus, The Jealous Wife, The Adulterous Falmouth Squire, ${ }^{6}$ Sir Cleges, Lybeaus Desconus y The Feasts of all Saints and All Souls.

Con respecto a los manuscritos en los que se conserva El Caballero Orfeo, Shuffelton revela que el manuscrito Auchinleck está dañado y carece del prólogo, sin embargo, contiene la versión más completa del poema. Es probable que las versiones del manuscrito Harley y del manuscrito Ashmole 61 procedan de una versión más antigua que fuera tan buena o mejor que el propio manuscrito Auchinleck, pero que después de al menos un siglo sometido a revisiones por parte de los copistas ha ido acumulando errores paulatinamente. Por otra parte, la versión del manuscrito Ashmole 61 parece ser mucho mejor que la versión del manuscrito Harley a pesar de que aquella carece de unos cincuenta versos que aparecen en la versión del manuscrito Auchinleck.

Finalmente, acabamos diciendo que la crítica moderna ha considerado al Caballero Orfeo como uno de los mejores romances ingleses, en especial, por la manera en la que el autor ha sabido adaptar y modernizar el mito griego a una nueva cultura más cercana a los lectores contemporáneos del poema inglés y a la magia desplegada en la configuración de un entorno lleno de magia y misterio. Sin embargo, se le achaca la carencia de valores relacionados con los ideales caballerescos tratados en otros romances medievales, y que las pruebas a las que se somete el rey inglés Orfeo no conducen finalmente a una autorrealización personal y/o espiritual. Quedan abierta, no obstante, muchas líneas de investigación con relación a este lay bretón compuesto en inglés medio (Middle English), una de ellas, si cabe, la comparación entre los síntomas postraumáticos que sufre o manifiesta Eurídice casi inmediatamente después de su experiencia sobrenatural y las que han experimentado o padecido aparentemente (tomados de una casuística real) aquellas personas que afirman haber pasado por una experiencia similar en los siglos XX y XXI, y que derivan finalmente en un "desorden de estrés postraumático (en inglés, PTSD= Posttraumatic Stress Disorder).

Fragmento del Caballero Orfeo (Sir Orfeo) y traducción de José Antonio Alonso Navarro. Edición digital de A. Laskaya y E. Salisbury en https://d.lib.rochester.edu/teams/text/laskayaand-salisbury-middle-english-breton-lays-sir-orfeo:

\footnotetext{
${ }^{4}$ Traducido por José Antonio Alonso Navarro. El caballero Isumbras. Asunción: Editorial UniNorte (Universidad del Norte), 2016.

${ }^{5}$ Traducido por José Antonio Alonso Navarro en Revista Linguae: Sociedad Española de Lenguas Modernas (SELM). No. 02. 2015. ISSN: 2386-8414.

${ }^{6}$ Traducido por José Antonio Alonso Navarro en Tres joyas de la literatura medieval inglesa: Incluye "El caballero Cleges" (Sir Cleges) además de El caballero Owain (Sir Owain) y La flor y la hoja. Asunción: Editorial Marben, 2014
} 
We redeth oft and findeth y-write, And this clerkes wele it wite,

Layes that ben in harping

Ben y-founde of ferli thing:

Sum bethe of wer and sum of wo, And sum of joie and mirthe also, And sum of trecherie and of gile, Of old aventours that fel while; And sum of bourdes and ribaudy, And mani ther beth of fairy.

Of al thinges that men seth,

Mest o love, forsothe, they beth.

In Breteyne this layes were wrought, First y-founde and forth y-brought, Of aventours that fel bi dayes,

Wherof Bretouns maked her layes.

When kinges might ovr y-here

Of ani mervailes that ther were, Thai token an harp in gle and game

And maked a lay and gaf it name.

Now of this aventours that weren y-falle

$Y$ can tel sum, ac nought alle.

Ac herkneth, lordinges that ben trewe, Ichil you telle of "Sir Orfewe."

Orfeo mest of ani thing

Lovede the gle of harping.

Siker was everi gode harpour

Of him to have miche honour.

Himself he lerned forto harp,

And leyd theron his wittes scharp;

He lerned so ther nothing was

A better harpour in no plas.

In al the warld was no man bore

That ones Orfeo sat bifore -

And he might of his harping here -

Bot he schuld thenche that he were

In on of the joies of Paradis,

Swiche melody in his harping is.

Orfeo was a king,

In Inglond an heighe lording,

A stalworth man and hardi bo;

Large and curteys he was also.

His fader was comen of King Pluto,

And his moder of King Juno,

That sum time were as godes yhold

For aventours that thai dede and told.

This king sojournd in Traciens, That was a cité of noble defens -

For Winchester was cleped tho

Traciens, withouten no. 
The king hadde a quen of priis

That was y-cleped Dame Heurodis,

The fairest levedi, for the nones,

That might gon on bodi and bones,

Ful of love and godenisse -

Ac no man may telle hir fairnise.

Bifel so in the comessing of May

When miri and hot is the day,

And oway beth winter schours,

And everi feld is ful of flours,

And blosme breme on everi bough

Over al wexeth miri anought,

This ich quen, Dame Heurodis

Tok to maidens of priis,

And went in an undrentide

To play bi an orchardside,

To se the floures sprede and spring

And to here the foules sing.

Thai sett hem doun al thre

Under a fair ympe-tre,

And wel sone this fair quene

Fel on slepe opon the grene.

The maidens durst hir nought awake,

Bot lete hir ligge and rest take.

So sche slepe til after none,

That undertide was al y-done.

Ac, as sone as sche gan awake,

Sche crid, and lothli bere gan make;

Sche froted hir honden and hir fete,

And crached hir visage - it bled wete -

Hir riche robe hye al to-rett

And was reveyd out of hir wit.

The two maidens hir biside

No durst with hir no leng abide,

Bot ourn to the palays ful right

And told bothe squier and knight

That her quen awede wold,

And bad hem go and hir at-hold.

Knightes urn and levedis also,

Damisels sexti and mo.

In the orchard to the quen hye come,

And her up in her armes nome,

And brought hir to bed atte last,

And held hir there fine fast.

Ac ever she held in o cri

And wold up and owy.

When Orfeo herd that tiding

Never him nas wers for nothing.

He come with knightes tene

To chaumber, right bifor the quene, 
And bi-held, and seyd with grete pité,

"O lef liif, what is te,

That ever yete hast ben so stille

And now gredest wonder schille?

Thy bodi, that was so white y-core,

With thine nailes is all to-tore.

Allas! thy rode, that was so red,

Is al wan, as thou were ded;

And also thine fingres smale

Beth al blodi and al pale.

Allas! thy lovesum eyyen to

Loketh so man doth on his fo!

A, dame, ich biseche, merci!

Lete ben al this reweful cri,

And tel me what the is, and hou,

And what thing may the help now."

Tho lay sche stille atte last

And gan to wepe swithe fast,

And seyd thus the King to:

"Allas, mi lord, Sir Orfeo!

Sethen we first togider were,

Ones wroth never we nere;

Bot ever ich have yloved the

As mi liif and so thou me;

Ac now we mot delen ato;

Do thi best, for y mot go."

"Allas!" quath he, "forlorn icham!

Whider wiltow go, and to wham?

Whider thou gost, ichil with the,

And whider y go, thou schalt with me."

"Nay, nay, Sir, that nought nis!

Ichil the telle al hou it is:

As ich lay this undertide

And slepe under our orchardside,

Ther come to me to fair knightes,

Wele y-armed al to rightes,

And bad me comen an heighing

And speke with her lord the king.

And ich answerd at wordes bold,

Y durst nought, no y nold.

Thai priked oyain as thai might drive;

Tho com her king, also blive,

With an hundred knightes and mo,

And damisels an hundred also,

$\mathrm{Al}$ on snowe-white stedes;

As white as milke were her wedes.

Y no seighe never yete bifore

So fair creatours y-core.

The king hadde a croun on hed;

It nas of silver, no of gold red, 
Ac it was of a precious ston -

As bright as the sonne it schon.

And as son as he to me cam,

Wold ich, nold ich, he me nam,

And made me with him ride

Opon a palfray bi his side;

And brought me to his palays,

Wele atird in ich ways,

And schewed me castels and tours,

Rivers, forestes, frith with flours,

And his riche stedes ichon.

And sethen me brought oyain hom

Into our owhen orchard,

And said to me thus afterward,

"'Loke, dame, tomorwe thatow be

Right here under this ympe-tre,

And than thou schalt with ous go

And live with ous evermo.

And yif thou makest ous y-let,

Whar thou be, thou worst y-fet,

And totore thine limes al

That nothing help the no schal;

And thei thou best so totorn,

Yete thou worst with ous y-born."'

When King Orfeo herd this cas,

"O we!" quath he, "Allas, allas!

Lever me were to lete mi liif

Than thus to lese the quen, mi wiif!"

He asked conseyl at ich man,

Ac no man him help no can.

Amorwe the undertide is come

And Orfeo hath his armes y-nome,

And wele ten hundred knightes with him,

Ich y-armed, stout and grim;

And with the quen wenten he

Right unto that ympe-tre.

Thai made scheltrom in ich a side

And sayd thai wold there abide

And dye ther everichon,

Er the quen schuld fram hem gon.

Ac yete amiddes hem ful right

The quen was oway y-twight,

With fairi forth y-nome.

Men wist never wher sche was bicome.

Tho was ther criing, wepe and wo!

The king into his chaumber is go,

And oft swoned opon the ston,

And made swiche diol and swiche mon

That neighe his liif was y-spent -

Ther was non amendement. 
He cleped togider his barouns,

Erls, lordes of renouns,

And when thai al y-comen were,

"Lordinges," he said, "bifor you here

Ich ordainy min heighe steward

To wite mi kingdom afterward;

In mi stede ben he schal

To kepe mi londes overal.

For now ichave mi quen y-lore,

The fairest levedi that ever was bore,

Never eft y nil no woman se.

Into wildernes ichil te

And live ther evermore

With wilde bestes in holtes hore;

And when ye understond that y be spent,

Make you than a parlement,

And chese you a newe king.

Now doth your best with al mi thing."

Tho was ther wepeing in the halle

And grete cri among hem alle;

Unnethe might old or yong

For wepeing speke a word with tong.

Thai kneled adoun al y-fere

And praid him, yif his wille were,

That he no schuld nought fram hem go.

"Do way!" quath he, "It schal be so!"

Al his kingdom he forsoke;

Bot a sclavin on him he toke.

He no hadde kirtel no hode,

Schert, ne no nother gode,

Bot his harp he tok algate

And dede him barfot out atte gate;

No man most with him go.

O way! What ther was wepe and wo,

When he that hadde ben king with croun

Went so poverlich out of toun!

Thurth wode and over heth

Into the wildernes he geth.

Nothing he fint that him is ays,

Bot ever he liveth in gret malais.

He that hadde $y$-werd the fowe and griis,

And on bed the purper biis,

Now on hard hethe he lith,

With leves and gresse he him writh.

He that hadde had castels and tours,

River, forest, frith with flours,

Now, thei it comenci to snewe and frese,

This king mot make his bed in mese.

He that had $y$-had knightes of priis

Bifor him kneland, and levedis, 
Now seth he nothing that him liketh,

Bot wilde wormes bi him striketh.

He that had y-had plenté

Of mete and drink, of ich deynté,

Now may he al day digge and wrote

Er he finde his fille of rote.

In somer he liveth bi wild frut,

And berien bot gode lite;

In winter may he nothing finde

Bot rote, grases, and the rinde.

Al his bodi was oway dwine

For missays, and al to-chine.

Lord! who may telle the sore

This king sufferd ten yere and more?

His here of his berd, blac and rowe,

To his girdel-stede was growe.

His harp, whereon was al his gle,

He hidde in an holwe tre;

And when the weder was clere and bright,

He toke his harp to him wel right

And harped at his owhen wille.

Into alle the wode the soun gan schille,

That alle the wilde bestes that ther beth

For joie abouten him thai teth,

And alle the foules that ther were

Come and sete on ich a brere

To here his harping a-fine -

So miche melody was therin;

And when he his harping lete wold,

No best bi him abide nold.

\section{Traducción del fragmento anterior a cargo de José Antonio Alonso Navarro:}

Con frecuencia leemos y hallamos escrito, y esto es algo que saben bien los eruditos, que los layes cantados versan sobre hechos portentosos. Algunos refieren gestas en el campo de batalla y otros, historias tristes; otros, historias alegres y de regocijo; y otros, cuentan historias de traición, de engaño o de aventuras que acontecieron en el pasado; otros, en cambio, contienen historias festivas e historias obscenas; sin embargo, son muchas las historias que hay en ellos sobre el mundo de las hadas. Mas, en verdad, la mayoría de las historias que se cuentan en ellos son de tema amoroso. Los primeros layes acerca de aventuras que acontecieron en el pasado fueron compuestos por bretones en Bretaña.

Cuando los reyes escuchaban en cualquier lugar acerca de sucesos asombrosos que habían sucedido, tomaban con regocijo el arpa cual trovador y componían un lay, poniéndole después un título al terminar. Bien, de tales aventuras acaecidas en el pasado, aunque no puedo contarlas todas, sí podré contar, al menos, alguna que otra. De modo que, mis leales señores, disponeos a escuchar ahora la historia del "caballero Orfeo", quien, por encima de todo, amaba la música alegre que brotaba del arpa. Y no había duda de que cualquiera que se preciara de ser un buen arpista se sentía muy honrado con su presencia. 
Sin ayuda de nadie, tras poner en ello todo su ingenio y destreza, aprendió a tocar el arpa. $Y$ tan bien aprendió a tocarlo, que no hubo en ningún lugar nadie mejor que él. En verdad, no había nadie en el mundo que, tras sentarse junto a Orfeo para escucharlo tocar el arpa, no pensara que se encontraba en el mismo Paraíso, tal era la melodía que salía de ella.

Orfeo era un rey y un alto señor en Inglaterra, además de un hombre robusto y valiente, generoso y cortés. Su padre descendía del rey Plutón y su madre de la reina Juno, los cuales, antaño, fueron tomados por dioses debido a las hazañas en las que ambos habían participado y a las gestas que habían contado. Este rey vivía en Tracia, ciudad de grandes fortificaciones. $Y$ es que Winchester se llamaba entonces Tracia, sin duda alguna. El rey estaba casado con la dama Eurídice, que era una reina de virtudes excelsas y, sin duda alguna, la dama más hermosa que pudiera caminar sobre la tierra, de una belleza tal que difícilmente se podría describir en su justa medida y, además, llena de amor y de bondad como ninguna otra. Ocurrió entonces a comienzos de mayo, cuando se asoma el buen tiempo y lejos quedan ya las lluvias invernales, y los campos se revisten de flores y los brotes de flor resplandecientes crecen sin rubor en cada rama de árbol con gran júbilo, que esta reina, la dama Eurídice, a última hora de la mañana, se llevó consigo a dos doncellas virtuosas con el fin de recrearse animadamente cerca de un jardin, ver brotar y expandirse las flores de aquí para allá, y escuchar a las aves trinar.

Las tres se sentaron debajo de un lindo manzano y en seguida, esta hermosa reina se quedó dormida encima de la hierba. Las doncellas no se atrevieron a despertarla, sino que la dejaron yacer allí y descansar plácidamente. De modo que estuvo durmiendo hasta pasado el mediodía y, al despertarse, comenzó a proferir gritos espantosos como si se hubiera vuelto loca. Se frotó las manos y los pies y se arañó el rostro hasta que comenzó a sangrar abundantemente. Hizo jirones sus vestiduras y pareció perder el juicio por completo. Las dos doncellas que la acompañaban ya no se atrevieron a quedarse con ella, así que sin dilación corrieron hacia el palacio para hacer saber a escuderos y caballeros que su reina se había vuelto loca, y pedirles que fuesen donde estaba ella y se hicieran cargo de la misma. Caballeros y también damas, y más de sesenta damiselas, se fueron a toda prisa al jardín donde estaba la reina. La tomaron en brazos, la llevaron finalmente a la cama, y alli la sujetaron con fuerza, mas, sin dejar de gritar, trató de salir de la cama. Cuando Orfeo escuchó lo ocurrido, se sintió más afligido que nunca. Se dirigió hasta el aposento de la reina con diez caballeros y ante ella se apostó. La miró y dijo con mucha pena:

- Oh, vida mía, ¿qué os sucede que habéis perdido la compostura que siempre guardasteis y, sin causa aparente, os habéis puesto a gritar de tal manera que espanto ha causado? Vuestro cuerpo, que era de un blanco tan refinado, habéis destrozado con vuestras uñas. ¡Ay! Vuestro rostro, lozano como era, está lívido ahora como si estuvieseis muerta. Y vuestros delicados dedos, miradlos, han perdido todo color y están cubiertos de sangre. ¡Ay! Vuestros encantadores ojos lanzan una mirada torva como la que se lanza al enemigo. ¡Ay, señora! Os lo suplico, por compasión, no gritéis más de manera tan lastimera, y decidme qué os perturba y cómo puedo ayudaros.

\footnotetext{
${ }^{7}$ El autor menciona a Juno como "rey", pero, en realidad, Juno era la diosa romana del matrimonio y la maternidad. Juno era la hija de Saturno y de Ops y hermana y esposa de Júpiter, con el que tuvo dos hijos, Marte y Vulcano y una hija, Lucina.
} 
Entonces, la dama, al fin, se calmó y se puso a llorar desconsoladamente mientras le decía al rey de esta manera:

- ¡Ay, mi señor Orfeo! Desde que nos conocimos, no nos hemos enfadado ni una sola vez, mas, muy al contrario, yo siempre os he amado con todo mi ser, como vos a mí. Sin embargo, ahora hemos de separarnos. Cuidaos mucho, pues debo marcharme.

- ¡Ay!, dijo el caballero, - jestoy perdido irremediablemente! ¿Adónde os vais a ir y con quién? Adonde vayáis vos, yo habré de acompañaros, y adonde vaya yo, vos habréis de acompañarme a mí.

- ¡No, no, señor! ¡No puede ser! Os diré por qué. Esta mañana, mientras dormía bajo nuestro jardín, se aproximaron a mí dos apuestos caballeros bien pertrechados con todas sus armas, y me pidieron que me dispusiera en seguida a hablar con su señor el rey. A lo que respondí con palabras un tanto osadas, pues ni me atreví a ello ni quise hacerlo. Viendo mi actitud, los caballeros se marcharon tan rápidamente como pudieron. Entonces, llegó su rey tan raudo y veloz como pudo con más de cien caballeros y cien damiselas, todos ellos montados en corceles tan blancos como la nieve y ataviados con atuendos tan blancos como la leche. Jamás había visto antes criaturas tan hermosas. El rey tenía en la cabeza una corona que no era ni de plata ni de oro rojo, sino de algún tipo de piedra preciosa que resplandecía con tanta intensidad como el sol.

Y tan pronto como se acercó a mí, tanto si quise como si no, me hizo cabalgar a su lado en un palafrén hasta conducirme a su palacio, el cual estaba suntuosamente decorado. Allí me mostró castillos y torres, ríos, bosques con flores y cada uno de sus majestuosos corceles. Después, me trajo de vuelta a nuestro jardín, y antes de marcharse me dijo de este modo:

- Señora, aseguraos de estar mañana aquí mismo bajo este manzano, pues os llevaremos a vivir con nosotros para siempre. Y si nos ponéis alguna traba a esto, no importa donde os halléis, iremos a por vos, y os descuartizaremos de tal manera que nada ni nadie podrá socorreros. Y aunque halláis sido descuartizada en mil pedazos, aun así, os llevaremos con nosotros.

Cuando el rey Orfeo escuchó esto dijo:

- ¡Ay, Dios mío! ¡Ay, ay! Más querría yo perder la propia vida que perder a mi esposa, la reina.

Después, pidió consejo a cuantos hombres pudo, pero sin que ninguno de ellos pudiera hacer nada. Al día siguiente, llegado el mediodía, cuando Orfeo ya había tomado sus armas y reunido a mil soldados bien pertrechados tan aguerridos como feroces, se encaminó con la reina hasta el manzano del jardín. Entonces, los soldados formaron dos hileras y se dispusieron a cada lado del lugar diciendo que alli se quedarían y morirían antes que permitir que se llevasen a la reina. Sin embargo, en medio de ellos, en un abrir y cerrar de ojos la reina fue arrebatada por arte de magia y encantamiento. Los hombres jamás supieron adónde se fue. A partir de entonces, el corazón de todos se turbó y se llenó de pena y de dolor. El rey se encerró en su aposento y varias veces cayó al suelo desmayado. Fueron tan grandes sus lamentos y gemidos que a punto estuvo de perder la vida sin remedio. Mandó llamar a sus barones, condes y grandes señores, y cuando estuvieron todos reunidos les dijo: 
- Señores, delante de todos vosotros dispongo que mi mayordomo real gobierne mi reino a partir de ahora. Él ocupará mi lugar y se encargará de administrar mis tierras hasta donde alcancen. He perdido a mi reina, la dama más hermosa sobre la faz de la tierra, de modo que en adelante jamás veré a otra mujer. Me adentraré en lo más desolado y salvaje del bosque sombrío, y allí moraré para siempre en compañía de las bestias silvestres, y cuando os llegue la noticia de mi muerte, formad un parlamento y elegid un nuevo rey. Ahora ocuparos de todos mis asuntos como corresponde.

Al terminar de hablar el rey, grandes y chicos prorrumpieron en grandes sollozos en el salón, y nadie pudo proferir ya palabra alguna. Al unísono todos juntos se pusieron de hinojos y le rogaron que no les abandonasen.

- ¡Basta!, dijo el rey, - se hará cómo os he dicho.

Al abandonar su reino por completo, solo se llevó consigo un manto de peregrino. No quiso llevarse ni túnica ni caperuza, ni camisa ni tampoco bienes de ninguna clase. Lo único de lo que no quiso desprenderse bajo ninguna circunstancia fue de su arpa, y con ella caminó descalzo por las calles, sin que nadie quisiera acompañarlo. ¡Ay, Dios mío! Cuántas lágrimas de dolor por él se derramaron, él que había sido todo un rey coronado, y ahora se marchaba de la ciudad como un mendigo. Y después de atravesar el bosque caminando sobre matorrales, Orfeo ${ }^{8}$ se interna en la parte más desolada y salvaje del mismo. Nada de lo que halla lo consuela, sino que vive constantemente presa de una gran aflicción. Él, que había llevado puesta la piel abigarrada y de color gris, y en el lecho había dormido encima de ropas de cama de color púrpura, ahora yace sobre ásperos matorrales, cubriéndose con hojas y hierba. Él, que había sido dueño de castillos y torres, de ríos y bosques con flores, ahora, se ponga a nevar o venga una helada, este rey no tiene más remedio que hacer su cama en el musgo. Él, que había tenido damas y caballeros de gran valía postrándose de hinojos ante él, no ve ahora nada que lo agrade, excepto sierpes que se arrastran junto a él. Él, que había tenido en abundancia los manjares y las bebidas más exquisitos ahora tiene que cavar y escarbar en busca de las raíces que necesita para sobrevivir. En verano se alimenta de frutos silvestres y de bayas de poco valor.

En invierno no encuentra nada para comer excepto raíces, hierba y corteza. Tantos rigores y penurias hicieron finalmente mella en su cuerpo, ahora consumido y agrietado. ¡Ay, Señor! ¿Quién puede narrar los padecimientos que tuvo que soportar este rey durante más de diez años? Tanto le creció la barba negra y áspera, que hasta la cintura le llegó. Y en cuanto a su arpa, que era lo que más feliz le hacía, este la escondió en el hueco de un árbol, mas cuando el tiempo estuvo despejado y soleado, Orfeo la cogió en seguida para consolarse y comenzó a tocarla a voluntad. Y en el instante en el que la música empezó a resonar por todo el bosque, todas las bestias salvajes que alli se hallaban se reunieron para deleite suyo en torno a él, y todas las aves que en el bosque estaban, se acercaron y se posaron en una zarza para escucharlo tocar con gran maestría. ¡Qué hermosa melodía brotó de ella! Y cuando dejó de tocar, las bestias se alejaron de él.

\footnotetext{
${ }^{8}$ Ahora el autor-narrador pasa del tiempo verbal en pasado al tiempo presente, que resulta más "visual" para una audiencia que esté escuchando el poema.
} 


\section{Bibliografía}

Allen, D., "Orpheus and Orfeo: The Dead and the Taken." Medium Aevum, 33 (1964), 102-11.

Alonso Navarro, José Antonio. Tres joyas de la literatura medieval inglesa: Incluye "El caballero Cleges" (Sir Cleges) además de El caballero Owain (Sir Owain) y La flor y la hoja. Asunción: Editorial Marben, 2014.

Alonso Navarro, José Antonio. Traducción del poema medieval inglés "El caballero Owain" "“Sir Owain"). (Traducción revisada y crítica) Revista Linguae: Sociedad Española de Lenguas Modernas (SELM). No. 01. 2014. ISSN: 2386-8414.

Alonso Navarro, José Antonio. Traducción del poema medieval inglés "El caballero Degaré" (Sir Degaré). Asunción: Editorial Marben, 2015.

Alonso Navarro, José Antonio. Traducción del poema medieval inglés "El caballero Corneus" (Sir Corneus). Revista Linguae: Sociedad Española de Lenguas Modernas (SELM). No. 02. 2015. ISSN: 2386-8414.

Alonso Navarro, José Antonio. Traducción del poema medieval inglés o lay bretón "El caballero Launfal" (Sir Launfal). Revista Linguae: Sociedad Española de Lenguas Modernas (SELM). ${ }^{\circ}$ 03. 2016. ISSN: 2386-8414.

Alonso Navarro, José Antonio. Traducción del poema medieval inglés "El caballero Isumbras" (Sir Isumbras) (Un romance/lay bretón medieval inglés en "Middle English"). UniNorte (Universidad del Norte): Asunción, Paraguay. 2016. Presentado por el Embajador del Reino Unido acreditado en Paraguay, doctor Jeremy Hobbs, $\mathrm{PhD}$ y el historiador y literato francés, doctor Alain SaintSäens, $\mathrm{PhD}$.

Alonso Navarro, José Antonio. Traducción del poema medieval inglés "La isla de las mujeres" (The Isle of Ladies) (Un poema medieval inglés en "Middle English"). UniNorte (Universidad del Norte): Asunción, Paraguay. 2017. Presentado por el Encargado de Negocios de la Embajador del Reino Unido en Asunción, Señor Nick White en representación del Excelentísimo Embajador del Reino Unido acreditado en Paraguay, doctor Jeremy Hobbs, PhD., y el historiador y literato francés, doctor Alain Saint-Säens, $\mathrm{PhD}$.

Alonso Navarro, José Antonio. Traducción del poema medieval inglés "El caballero Eglamour de Artois" (Sir Eglamour of Artois) (Un poema medieval inglés en "Middle English"). UniNorte (Universidad del Norte): Asunción, Paraguay. 2018.

Alonso Navarro, José Antonio. Dos divertidos cuentos medievales ingleses: traducción del poema medieval inglés El cuento del bacín (The Tale of the Basin) y de La dama priora (The Lady Prioress). Prólogo del doctor Miguel Ayerbe (Universidad del País Vasco en Vitoria, España) y notas de la doctora Melissa M. Furrow (Dalhousie University, Nova Scotia, Canada). Asunción: Universidad del Norte (UniNorte), 2018.

Bliss, A. J., ed. Sir Orfeo. 2nd ed. Oxford: Clarendon Press, 1966.

Laskaya, Anne \& Salisbury, Eve. (Ed.). The Middle English Breton Lays. Michigan: Medieval Institute Publications, 1995.

Lerer, Seth. "Artifice and Artistry in Sir Orfeo." Speculum 60 (1985), 92-109.

Liuzza, Roy Michael. "Sir Orfeo: Sources, Traditions, and the Poetics of Performance." Journal of Medieval and Renaissance Studies 21 (1991), 269-84.

Magnúsdóttir, Ásdís R. La Voix du cor. Amsterdam: Rodopi, 1998.

Rumble, Thomas, ed. The Breton Lays in Middle English. Detroit, MI: Wayne State University Press, 1965.

Shuffelton, George. (Ed). Codex Ashmole 61: A Compilation of Popular Middle English Verse.

Michigan: Medieval Institute Publications, 2008.

Zipes, Jack. The Oxford Companion to Fairytales. Oxford: Oxford University Press, 2009.

\section{Versiones digitales del Caballero Orfeo}

Laskaya, Anne y Salisbury, Eve. https://d.lib.rochester.edu/teams/text/laskaya-and-salisbury-middleenglish-breton-lays-sir-orfeo 
Shuffelton, George. https://d.lib.rochester.edu/teams/text/shuffelton-codex-ashmole-61-sir-orfeo

\section{Manuscritos}

National Library of Scotland MS Advocates 19.2.1, fols. 299a (stub)-303ra; also known as the Auchinleck MS (A).

British Library MS Harley 3810, fols. 1a-10a (H).

Bodleian Library MS Ashmole 61, fols. 151a-156a (B).

\section{Edición facsímile}

The Auchinleck Manuscript. National Library of Scotland. Advocates MS. 19.2.1. With introduction by Derek Pearsall and I. C. Cunningham. London: Scolar Press, in association with The National Library of Scotland, 1979. 